\title{
Compreensão Emocional da Morte Pelas Crianças em Idade Pré-escolar: Uma Dimensão Esquecida
}

\section{Preschool Children's Emotional Understanding of Death: A Forgotten Dimension}

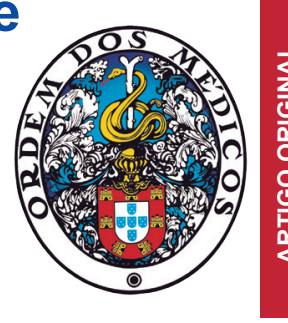

Filipa Martins SILVA $\triangle \triangle^{1}$, Ana Filipa LOPES ${ }^{1}$, Vânia CARNEIRO², Álvaro CAMPELO ${ }^{3}$

Acta Med Port 2020 Oct;33(10):649-656 - https://doi.org/10.20344/amp.12815

\section{RESUMO}

Introdução: É ainda parca a evidência científica quanto ao entendimento que as crianças têm sobre o conceito de morte, recentemente apontado pela International Children's Palliative Care Network como área prioritária de investigação. Em particular, a eviç̧ão da emoção nesta área de investigação é uma lacuna importante. Este estudo visa desenvolver uma visão aprofundada da dimensão emocional da compreensão da morte pela criança, procurando, também, relacioná-la com a dimensão cognitiva.

Material e Métodos: Entrevistámos crianças (três a seis anos), com recurso a um livro ilustrando o cenário hipotético em que uma criança se deparava com a de morte de um familiar. Colocámos questões para avaliar os subconceitos cognitivos da morte e a dimensão emocional (o que sentiria a criança e o que lhe devia ser dito pelos pais).

Resultados: Dos 54 participantes, a maioria disse que a criança se sentiria triste $(n=46,85 \%)$ e que os pais deveriam informá-la $(n=$ 47, 87\%); estas respostas não variaram significativamente com a idade. A compreensão cognitiva do conceito de morte das crianças que referiram a tristeza foi significativamente superior.

Discussão: Mesmo as crianças mais pequenas sentem a morte, não sendo possível desligar as compreensões cognitiva e emocional. Adicionalmente, as crianças devem ser informadas, com vista a uma elaboração adequada e multidimensional da morte.

Conclusão: Este estudo fornece informação valiosa aos profissionais de saúde e outros adultos interessados sobre a forma como a criança em idade pré-escolar se posiciona em relação à morte.

Palavras-chave: Atitude Perante a Morte; Criança em Idade Pré-escolar; Cuidados Paliativos; Psicologia da Criança

\section{ABSTRACT}

Introduction: Scientific evidence regarding children's understanding of the concept of death is scarce. This has recently been pointed out by the International Children's Palliative Care Network as a priority area of research. In particular, the avoidance of emotion in this area of research is an important shortcoming. This study aims to develop an in-depth view of the emotional dimension of the child's understanding of death, also seeking to relate it to the cognitive dimension.

Material and Methods: We interviewed children (three to six years old) using a book illustrating a hypothetical scenario in which a child faced the death of a relative. We asked questions to assess the cognitive subconcepts of death and the emotional dimension (what the child would feel and what parents should say).

Results: Of the 54 participants, the majority said that the child would feel sad $(n=46,85 \%)$ and that parents should inform her/him ( $n$ $=47,87 \%$ ); these responses did not vary significantly with age. The cognitive understanding of the concept of death in children who reported sadness was significantly higher.

Discussion: Even the youngest children feel death, and it is not possible to disconnect cognitive and emotional understanding. Additionally, children should be informed in order to foster a proper and multidimensional elaboration of death.

Conclusion: This study provides valuable information to health professionals and other interested adults about the way preschoolers position themselves in relation to death.

Keywords: Attitude to Death; Child, Preschool; Palliative Care; Psychology, Child

\section{INTRODUÇÃO}

A compreensão geral do conceito de morte é habitualmente subdividida, tendo por base estudos de desenvolvimento infantil, em quatro subcomponentes primários: universalidade (todas as coisas vivas morrem), irreversibilidade (uma vez morto, morto para sempre), não-funcionalidade (todas as funções do corpo cessam) e causalidade (o que causa a morte). ${ }^{1,2} \mathrm{Em}$ cada idade, há variabilidade na compreensão da morte, tendo-se tradicionalmente atribuído mais relevância ao estado de desenvolvimento cognitivo, ${ }^{1,2}$ assumindo-se, de uma perspetiva puramente desenvolvimental, que essa compreensão progride ao longo de um processo linear. ${ }^{3}$ Contudo, sabe-se, atualmente, que o processo é mais complexo, tendo algumas crianças uma visão mais sofisticada da morte e do morrer do que outras, dependendo de outros fatores, nomeadamente emocionais, sociofamiliares e culturais. ${ }^{3}$

De facto, a evicção da emoção na investigação sobre a compreensão da morte pela criança tem sido uma lacuna importante. ${ }^{4}$ Neste domínio, há apenas alguns estudos que se centram sobretudo no medo da morte. , $^{1,56}$ No entanto, embora contemplem um componente emocional, este é interpretado de um modo isolado, estando a noção de compreensão de morte restrita ao domínio biológico, assumindo-se medidas puramente cognitivas para avaliar a

1. Departamento de Pedopsiquiatria e Saúde Mental da Infância e Adolescência. Centro Hospitalar Universitário do Porto. Porto. Portugal.

2. Departamento de Psicologia Clínica e da Saúde. Faculdade de Ciências Sociais e Humanas. Universidade Fernando Pessoa. Porto. Portugal.

3. Faculdade de Ciências Humanas e Sociais. Universidade Fernando Pessoa. Centro em Rede de Investigação em Antropologia (CRIA). Porto. Portugal.

$\triangle$ Autor correspondente: Filipa Martins Silva. anafilipacmsilva@gmail.com

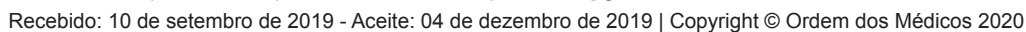


maturidade do conceito de morte. Portanto, falta evidência integradora de medidas cognitivas e afetivas, que explore uma noção de 'preparação' da criança para lidar com a morte que vá além da tradicional 'capacidade cognitiva' para compreender a morte. ${ }^{4}$

Este conhecimento mais profundo e integrador, sobre a compreensão do conceito de morte pela criança, poderá ser especialmente útil ao nível dos cuidados de saúde, onde se recomenda, no geral, que a morte seja discutida com as crianças de forma honesta, concreta, sem termos ambíguos e de acordo com o seu nível de compreensão. ${ }^{1}$ Efetivamente, a International Children's Palliative Care Network realizou recentemente um estudo Delphi, de modo a identificar as prioridades de investigação ao nível global em Cuidados Paliativos Pediátricos, com consenso em 26 áreas, tendo sido a primeira a "Compreensão da criança da morte e do processo de morrer" (Children's understanding of death and dying). ${ }^{3}$ Assim, o estudo da compreensão do conceito de morte pelas crianças é de máxima prioridade, sobre o qual deve ser construída evidência científica. Acresce que em Portugal, até à data, não foi desenvolvido qualquer trabalho de investigação sobre a matéria. Este estudo foi concebido como forma de dar resposta a esta importante área de investigação, visando, portanto, desenvolver uma visão aprofundada da dimensão emocional da compreensão da morte pela criança, procurando, também, relacioná-la com a dimensão cognitiva.

\section{MATERIAL E MÉTODOS}

O estudo, sendo parte de um projeto de investigação multidimensional e etnográfica mais abrangente, que visa também examinar a compreensão da morte pela criança no seu contexto sociocultural, foi aprovado pela Comissão de Ética do Centro Hospitalar de São João/ Faculdade de Medicina da Universidade do Porto.

Seguindo uma abordagem transversal, realizámos entrevistas a crianças, num ambiente naturalista. A população de estudo foram crianças de três a seis anos de idade, uma vez que nesta faixa etária há um desenvolvimento importante na compreensão dos fenómenos biológicos ${ }^{7}$ e pela evidência recente de que as crianças desta idade têm um melhor entendimento da morte do que se pensava previamente. ${ }^{7,8}$ À semelhança de outros estudos nesta área, ${ }^{7-9}$ este estudo centrou-se em crianças provenientes de famílias de classe média. Assumindo uma escolha de conveniência, realizámos o estudo na cidade do Porto. Com base no esquema de classes de J. Goldthorpe ${ }^{10}$ e consultando os dados obtidos nos Censos 2011, ${ }^{11}$ considerámos como zonas de classe média as freguesias do Porto com $70 \%$ a $90 \%$ de população empregada nos seguintes grupos de profissões: quadros superiores da administração pública, dirigentes e quadros superiores de empresas; pessoal dos serviços e vendedores; pessoal administrativo e similares; técnicos e profissionais de nível intermédio; especialistas das profissões intelectuais e científicas. Da aplicação deste critério, selecionámos nove freguesias. Realizámos, posteriormente, um levantamento dos estabelecimentos com ensino pré-escolar (crianças de três a seis anos) nessas freguesias, categorizando-as em públicas $(n=29)$ e privadas $(n=74)$. Dentro de cada categoria, escolhemos, de um modo aleatório, duas escolas. Contactámos a direção dos respetivos agrupamentos de escolas no sentido de informar sobre o estudo, solicitando a sua participação. Após aceitação, efetuámos a devida articulação com as educadoras de infância, no sentido de se contactar todos os pais, para explicação e convite à participação dos seus filhos no estudo. Demos oportunidade aos pais para colocação de dúvidas e esclarecimentos que considerassem necessários, com a garantia de privacidade e confidencialidade, bem como a possibilidade de desistência a qualquer momento da participação no estudo, conforme constou no documento do consentimento informado. No total, obtivemos 54 autorizações para participação no estudo. Cumprido este procedimento, agendámos as entrevistas com as crianças.

As entrevistas, cada uma com duração aproximada de uma hora, foram levadas a cabo pelos autores um e três, ambos profissionais na área de saúde mental infantil, com experiência clínica em técnicas de entrevista a crianças em idade pré-escolar. Entrevistámos cada criança individualmente, na respetiva escola, no primeiro semestre de 2018. Para instrumento de recolha de dados realizámos, à semelhança de um estudo recente, ${ }^{9}$ uma adaptação dos protocolos da tradicional investigação do desenvolvimento cognitivo, de modo a criar cenários hipotéticos mais realistas e próximos das experiências do dia-a-dia da criança (e não questões no abstrato), tendo sido ainda acrescentadas questões sobre as dimensões emocionais da sua experiência. Assim, construímos um livro com ilustrações para ser usado nestas entrevistas. A primeira e última secções desse livro incluíam questões sobre processos da vida, uma vez que, embora o interesse principal neste estudo fosse a compreensão da morte pela criança, uma entrevista totalmente focada na morte poderia conferir um potencial perturbador para as crianças ${ }^{9}$; por não se encontrarem no âmbito deste artigo, estas questões não serão aqui abordadas. A secção intermédia do livro tinha representadas imagens que correspondiam às questões sobre a morte. Nesta secção, o entrevistador começava por mostrar à criança uma ilustração do João ou da Ana (nomes escolhidos por serem comuns na sociedade portuguesa), uma criança que se assemelhava ao participante em termos de idade e sexo (criámos, portanto, versões diferentes para meninos e meninas). De seguida, era apresentada ao participante uma ilustração de um cenário hipotético de morte de um(a) tio(a), experienciados pelo(a) João ou Ana. A metade das crianças apresentámos o cenário de morte de um tio e, à outra metade, o de uma tia. O investigador colocava, de seguida, uma série de questões, com vista a uma avaliação multidimensional da compreensão da morte [estrutura da entrevista no Apêndice 1 (ver Apêndice 1: https://www.actamedicaportuguesa.com/revista/index.php/amp/article/view/12815/Apendice_01.pdf)]. Para a avaliação da dimensão cognitiva da compreensão da morte, colocámos questões relativas aos subconceitos 
de morte, definidas em investigações do desenvolvimento cognitivo prévias: irreversibilidade, não-funcionalidade, universalidade e causalidade. ${ }^{12,13}$ Por outro lado, a avaliação da dimensão emocional procurou que a criança elaborasse acerca dos sentimentos que podem surgir face à morte, averiguando também se a criança reconhecia como normativas algumas emoções em específico, nomeadamente tristeza, medo e zanga ("Como achas que o(a) João ou Ana se sente em relação à morte do(a) seu tio(a)?"; caso a criança não referisse emoções que se pudessem categorizar como tristeza, medo e zanga, deveria ser questionado diretamente: "Achas que o(a) João ou Ana se sente triste/ com medo/ zangado em relação à morte do(a) seu tio(a)/ cão/planta?"). Avaliámos ainda o padrão comunicacional dos pais esperado pelas crianças numa situação de morte ("O que achas que os pais do(a) João ou Ana lhe devem dizer em relação à morte do(a) seu tio(a)/cão/planta?"). Previamente à aplicação no estudo, testámos este instrumento numa amostra de conveniência com crianças entre os três a seis anos, para avaliar a sua compreensibilidade e adequabilidade. As entrevistas foram gravadas e posteriormente transcritas integralmente.

Quanto à análise dos dados, calculámos uma pontuação geral da compreensão cognitiva da morte, somando as respostas biologicamente corretas da criança relativas aos diferentes subconceitos (valores entre 0 e 14). Quanto à análise qualitativa das restantes dimensões, após uma familiarização inicial com os dados, efetuámos uma análise temática. ${ }^{14,15} \mathrm{O}$ autor um desenvolveu um esquema de codificação inicial e realizou a indexação através de comparação constante dentro e entre os casos, procurando temas recorrentes e outros significados padronizados expressos pelos participantes. Adicionalmente, categorias derivadas ou emergentes foram desenvolvidas e refinadas num processo iterativo. $\mathrm{O}$ autor dois codificou metade das transcrições, independentemente do autor um, e as comparações foram usadas para confirmar ou discutir e ajustar a análise. No que concerne à dimensão emocional, quando questionados sobre as emoções que podem surgir face à morte, as crianças deram uma variedade de respostas que se codificaram em seis categorias: "Triste", "Com medo", "Zangado", "Emoções positivas", "Resposta confusa" e "Não sei". As respostas a esta questão podiam ter mais do que um código. Relativamente ao padrão comunicacional, codificámos as respostas à pergunta sobre o que os pais devem dizer perante essa situação em cinco categorias mutuamente exclusivas: "Dizer que morreu", "Não contar", "Não é verdade", "Resposta confusa" e "Não sabe". Adicionalmente, a categoria "Dizer que morreu" subdividiu-se em quatro subcategorias: "e dar suporte (emocional e/ou espiritual)", "e a causa", "e é reversível" e "e é irreversível". Excetuando as subcategorias referentes à reversibilidade que eram mutuamente exclusivas entre si, as restantes podiam sobrepor-se. Para a análise estatística (quer da dimensão cognitiva, quer da emocional), recorremos ao software IBM SPSS Statistics for Windows, Version 25.0. Todos os valores de $p$ reportados são bicaudados, assumindo-se um valor de $p$ de 0,05 indicativo de significância estatística. Realizámos o teste à normal distribuição dos dados com recurso aos testes de Kolmogorov-Smirnov e de Shapiro-Wilk ou pela análise dos valores de assimetria e achatamento (valores máximos toleráveis de 1). Recorremos ao teste $t$ para comparação de médias e ao coeficiente de correlação de Pearson $(r)$ para avaliar correlações paramétricas.

\section{RESULTADOS}

Entrevistámos 54 crianças portuguesas, com naturalidade e residência no Porto, em zonas de classe média. A amostra incluiu 24 participantes do sexo feminino (44\%) e 30 do sexo masculino (56\%). As suas idades variaram

Tabela 1 - Resposta emocional da criança face à morte do familiar

\begin{tabular}{|c|c|c|}
\hline Categorias & n (\%) & Respostas representativas \\
\hline Triste & $\begin{array}{c}46 \\
85 \%\end{array}$ & $\begin{array}{l}\text { "Triste" } \\
\text { "Triste e a chorar" } \\
\text { "A chorar, triste e com amor" } \\
\text { "Triste e vai procurar o tio" } \\
\text { "Triste e com saudades de quando brincavam juntas" } \\
\text { "Triste e com saudades da tia" } \\
\text { "Triste, com o coração estragado em mil bocadinhos" } \\
\text { "Triste, mas teve que viver a vida dele" }\end{array}$ \\
\hline Com medo & $\begin{array}{c}11 \\
20 \%\end{array}$ & [sempre em sobreposição com outras categorias - ver Tabela 2] \\
\hline Zangado & $\begin{array}{c}\mathbf{8} \\
15 \%\end{array}$ & [sempre em sobreposição com outras categorias - ver Tabela 2] \\
\hline Emoções positivas & $\begin{array}{c}2 \\
4 \%\end{array}$ & $\begin{array}{l}\text { "Feliz" } \\
\text { "Sentiu-se bem" }\end{array}$ \\
\hline Resposta confusa & $\begin{array}{c}3 \\
6 \%\end{array}$ & $\begin{array}{l}\text { "Ele viu-o num caixote e sentiu-se mal" } \\
\text { "Ficou muito bem, com medo e zangado" } \\
\text { "Morrido" }\end{array}$ \\
\hline Não sei & $\begin{array}{c}2 \\
4 \%\end{array}$ & "Não sei" \\
\hline
\end{tabular}

N.R.: As percentagens apresentadas referem-se ao total de crianças entrevistadas $(n=54)$ 
Tabela 2 - Efeito da idade no reconhecimento emocional

\begin{tabular}{lccc}
\hline & \multicolumn{2}{c}{ Idade (média \pm DP) } \\
Categorias & Não & Sim & $p$ \\
\hline Triste & $56,5 \pm 11,8$ & $62,0 \pm 9,4$ & 0,146 \\
Com medo & $61,5 \pm 10,1$ & $60,1 \pm 9,4$ & 0,675 \\
Zangado & $61,6 \pm 9,8$ & $59,1 \pm 11,1$ & 0,521 \\
\hline
\end{tabular}

N.R.: "Não" significa que a criança não mencionou essa categoria; "Sim" significa que criança mencionou essa categoria. Pela reduzida dimensão amostral, não se testaram as restantes categorias. Recorremos ao teste $t$ para comparação de médias. Todos os valores de $p$ reportados são bicaudados, assumindo-se um valor de $p$ de 0,05 indicativo de significância estatística.

entre um mínimo de três anos e cinco meses e um máximo de seis anos e seis meses, com uma média de cinco anos e um mês.

\section{Dimensão emocional}

A maioria das crianças disse que o/a João/Ana se sentiria triste face à morte do familiar $(n=46,85 \%)$, com respostas como: "Triste e a chorar", "Triste e com saudades de quando brincavam juntas", "Triste, com o coração estragado em mil bocadinhos" e "Triste, mas teve que viver a vida dele" (Tabela 1). Esta resposta não variou de modo significativo com a idade (Tabela 2). A segunda emoção mais frequentemente referida pelas crianças foi medo $(n=$ $11,20 \%)$, seguida da zanga $(n=8,15 \%)$ (Tabela 1). Uma vez mais, as respostas "Com medo" e "Zangado" não variaram de modo significativo com a idade (Tabela 2). Algumas crianças $(n=2)$ responderam que o/a João/Ana teria emoções positivas ("Feliz" e "Sentiu-se bem") em resposta à morte do familiar. Três crianças deram respostas confusas (por exemplo: "Ele viu-o num caixote e sentiu-se mal", "Ficou muito bem, com medo e zangado" e "Morrido"). Por fim, duas crianças responderam que não sabiam o que o/a João/Ana sentiriam perante a morte do familiar (Tabela 1). As categorias "Com medo" e "Zangado" surgiram sempre em sobreposição com outras categorias (Tabela 3).

\section{Padrão comunicacional}

Quando questionados sobre o que achavam que os pais deviam dizer ao/à João/Ana sobre a morte (Tabela
4), a maior parte das crianças ( $n=47,87 \%$ ) respondeu que deveriam dizer-lhes que o familiar tinha morrido (por exemplo: "(...) que a tia morreu senão ela depois não sabia" e"(...) que a tia morreu porque ela pode pensar que a tia não está morta e está"). Por outro lado, quatro crianças referiram que os pais não deveriam contar-Ihes, com respostas como: "(...) não devem contar porque senão ela fica ainda mais triste" e "(...) não devem contar à Ana que a tia morreu; devem dizer-lhe para não pensar nisso". As respostas "Dizer que morreu" e "Não contar" não variaram de modo significativo com a idade (Tabela 5). Uma criança referiu que os pais deveriam dizer que a situação de morte não era verdade (“(...) que é a brincar"). Foi também dada uma resposta confusa ("(...) que não se pode atirar pela janela, nem se diz asneiras”). Por fim, uma criança referiu não saber o que os pais deviam dizer.

Das crianças que referiram que os pais deveriam abordar com eles a morte (Tabela 4), quatro acrescentaram que essa informação deveria ser acompanhada de suporte emocional e espiritual, com respostas como: "(devem dizer-lhe) que eles também estão tristes”, “(...) para ela pensar sempre no seu tio e rezar" e "(...) para irem à igreja para rezar e dizer a Jesus que querem que o tio fique vivo para sempre". Três crianças referiram também a necessidade de serem informadas sobre a causa da morte, por exemplo: "(...) a tia acertou num pico e morreu" e "(...) morreu porque estava muito velhinho". Adicionalmente, quatro crianças mencionaram que deveria ser-lhe dito que a morte era reversível, por exemplo: "(...) que o tio foi para o Jesus e vai voltar quando estiver melhor; e os pais devem dizer ao Jesus para o tio voltar", "(...) que ele tem que encontrar o tio, para o ir buscar" e "(...) para levar o tio ao hospital". Por outro lado, uma criança referiu o oposto, isto é, que deveria ser esclarecida a irreversibilidade da morte, com a resposta "(...) morreu e nunca mais vai voltar".

\section{Relação entre as dimensões cognitiva e emocional}

A média da pontuação geral da compreensão de morte foi de $8,61( \pm 0,4)$, com um mínimo de dois e um máximo de 14. Existe uma correlação positiva (testada através do

Tabela 3 - Sobreposição de respostas Emocionais da criança face à morte do familiar

\begin{tabular}{|c|c|c|}
\hline Categorias sobrepostas & $\mathbf{n}$ & Respostas representativas \\
\hline $\begin{array}{l}\text { Triste } \\
\& \\
\text { Com medo }\end{array}$ & 5 & "Triste e com medo" \\
\hline $\begin{array}{l}\text { Triste } \\
\& \\
\text { Zangado }\end{array}$ & 2 & "Triste e zangado" \\
\hline $\begin{array}{l}\text { Com medo } \\
\& \\
\text { Zangado }\end{array}$ & 1 & "Com medo e zangado" \\
\hline $\begin{array}{l}\text { Triste } \\
\& \\
\text { Com medo } \\
\& \\
\text { Zangado }\end{array}$ & 5 & $\begin{array}{l}\text { "Triste, com medo e zangada" } \\
\text { "Triste, com medo e zangado e chorou; depois não queria ir passear sozinho" }\end{array}$ \\
\hline
\end{tabular}


Tabela 4 - O que os pais devem dizer à criança face à morte do familiar

\begin{tabular}{|c|c|c|}
\hline Categorias & $\mathbf{n}$ & Respostas representativas \\
\hline Dizer que morreu & $\begin{array}{c}47 \\
87 \%\end{array}$ & $\begin{array}{l}\text { "(...) que a tia morreu senão ela depois não sabia" } \\
\text { "(..) que a tia morreu porque ela pode pensar que a tia não está morta e está" }\end{array}$ \\
\hline $\begin{array}{l}\text { dar suporte } \\
\text { emocional } \\
\text { espiritual }\end{array}$ & 4 & $\begin{array}{l}\text { "(...) que eles também estão tristes" } \\
\text { "(..) para irem à igreja para rezar e dizer a Jesus que querem que o tio fique vivo para sempre" } \\
\text { "(...) para ela pensar sempre no seu tio e rezar" } \\
\text { "(..) que o tio foi para o Jesus e vai voltar quando estiver melhor; e os pais devem dizer ao Jesus para o tio } \\
\text { voltar" }\end{array}$ \\
\hline a causa & 3 & $\begin{array}{l}\text { "(...) já estava a ficar muito velhinha e que já estava a ficar a morrer" } \\
\text { "(...) a tia acertou num pico e morreu" } \\
\text { "(..) morreu porque estava muito velhinho" }\end{array}$ \\
\hline é reversível & 4 & $\begin{array}{l}\text { "(...) que ele tem que encontrar o tio, para o ir buscar" } \\
\text { "(..) para levar o tio ao hospital" } \\
\text { "(...) para dizer a Jesus que querem que o tio fique vivo para sempre" } \\
\text { "(..) que o tio foi para o Jesus e vai voltar quando estiver melhor; e os pais devem dizer ao Jesus para o tio } \\
\text { voltar" }\end{array}$ \\
\hline é irreversível & 1 & "(...) morreu e nunca mais vai voltar" \\
\hline Não contar & $\begin{array}{c}4 \\
7 \%\end{array}$ & $\begin{array}{l}\text { "(...) não devem contar porque senão ela fica ainda mais triste” } \\
\text { "(...) não devem contar ao João porque ele está zangado, não quer falar com ninguém..." } \\
\text { "(...) devem dizer à Ana para não ter medo, mas não devem contar à Ana que a tia morreu; devem dizer-Ihe } \\
\text { para não pensar nisso" } \\
\text { "(...) devem dizer que a Ana pode ir a um sítio pôr uma flor ao tio, mas não devem contar à Ana que o tio } \\
\text { morreu porque senão ela fica muito triste" }\end{array}$ \\
\hline Não é verdade & $\begin{array}{c}1 \\
2 \%\end{array}$ & "(...) que é a brincar" \\
\hline Resposta confusa & $\begin{array}{c}1 \\
2 \%\end{array}$ & "(...) que não se pode atirar pela janela, nem se diz asneiras" \\
\hline Não sabe & $\begin{array}{c}1 \\
2 \%\end{array}$ & "Não sei" \\
\hline
\end{tabular}

coeficiente de correlação de Pearson), estatisticamente significativa, entre a idade e a pontuação geral de compreensão cognitiva de morte $(r=0,32 ; p=0,02)$. No sentido de avaliar a relação entre as dimensões cognitiva e emocional da perceção da morte, procurámos perceber se a pontuação geral da compreensão cognitiva da morte variava consoante a resposta emocional referida pela criança. Verificámos que a média da pontuação geral da compreensão cognitiva do conceito de morte das crianças que responderam que o/a João/Ana se sentiria triste face à morte do familiar $(9,0 \pm 2,9)$ foi significativamente superior à das que não referiram esse estado emocional $(6,6 \pm 2,6$; $p=0,038$ ) (Tabela 6). Quanto às respostas "Com medo" e "Zangado", não se verificaram diferenças estatisticamente significativas.

Tabela 5 - Efeito da idade no que os pais devem dizer à criança face à morte do familiar

\begin{tabular}{lccc}
\hline & \multicolumn{3}{c}{ Idade (média \pm DP) } \\
Categorias & Não & Sim & $p$ \\
\hline Dizer que morreu & $64,1 \pm 9,4$ & $60,1 \pm 10,0$ & 0,408 \\
Não Contar & $61,0 \pm 10,1$ & $64,3 \pm 8,1$ & 0,530 \\
\hline
\end{tabular}

N.R.: "Não" significa que a criança não mencionou essa categoria. "Sim" significa que criança mencionou essa categoria. Pela reduzida dimensão amostral, não se testaram as restantes categorias. Recorremos ao teste $t$ para comparação de médias. Todos os valores de $p$ reportados são bicaudados, assumindo-se um valor de $p$ de 0,05 indicativo de significância estatística. "Não" significa que a criança não mencionou esse estado emocional; "Sim" significa que criança mencionou esse estado emocional.

\section{DISCUSSÃO}

De um modo geral, verificámos que a maioria das crianças entrevistadas, em idade pré-escolar, reconhece que uma situação de morte despoleta um estado emocional de tristeza, sendo a segunda emoção mais frequentemente referida a de medo, seguida da zanga. Este reconhecimento emocional não difere de modo significativo com a idade. Um número reduzido de crianças refere emoções positivas em resposta à morte ou demonstram dificuldades no reconhecimento emocional, fornecendo respostas confusas ou verbalizando, mesmo, desconhecimento na identificação emocional. Adicionalmente, e independentemente da idade, a maioria dos entrevistados considera que a criança deve ser informada pelos pais da morte de um familiar.

Tabela 6 - Efeito da compreensão cognitiva no reconhecimento emocional

\begin{tabular}{lccc}
\hline & \multicolumn{3}{c}{$\begin{array}{c}\text { Compreensão cognitiva } \\
\text { (média } \pm \text { DP) }\end{array}$} \\
Categorias & Não & Sim & $p$ \\
\hline Triste & $6,6 \pm 2,6$ & $9,0 \pm 2,9$ & $0,038^{\star}$ \\
Com medo & $8,6 \pm 3,1$ & $8,6 \pm 2,5$ & 0,975 \\
Zangado & $8,7 \pm 3,1$ & $8,4 \pm 1,8$ & 0,809 \\
\hline
\end{tabular}

* significância estatística $(p<0,05)$

N.R.: "Não" significa que a criança não mencionou essa categoria; "Sim" significa que criança mencionou essa categoria. Pela reduzida dimensão amostral, não se testaram as restantes categorias. Recorremos ao teste t para comparação de médias. Todos os valores de p reportados são bicaudados, assumindo-se um valor de $p$ de 0,05 indicativo de significância estatística. 
Por último, verificámos que a pontuação geral da compreensão cognitiva da morte, nas crianças que reconhecem a tristeza como normativa perante a situação de parte, é significativamente superior em relação às crianças que não o fazem.

Um dos achados mais relevantes a destacar deste estudo é o facto de evidenciar que as crianças em idade pré-escolar, mesmo as mais pequenas, reconhecem como normativa a reação de tristeza perante o cenário de morte de alguém próximo. Este achado vai ao encontro dos resultados de um estudo recente, de abordagem similar, em que a maioria das crianças ( $86 \%)$ nesta faixa etária, mesmo as mais pequenas, referiam a tristeza como normativa perante a morte; nesse estudo algumas crianças (3\%) também mencionam emoções positivas. ${ }^{16}$ Por outro lado, este achado contrasta com estudos prévios que mostram que, em termos emocionais, o medo da morte predomina nestas idades. $6,17,18$ No entanto, estes estudos seguem uma abordagem maioritariamente focada na investigação do desenvolvimento cognitivo, restringindo a dimensão emocional ao "medo da morte", essencialmente para demonstrar que a aprendizagem dos factos biológicos sobre a morte pode mitigar esse medo, eliminando a confusão e questões sem resposta que surgem quando se tem um conceito imaturo da morte. ${ }^{6}$ Acresce que, nestes estudos, as questões são colocadas às crianças de modo abstrato, e não através de modelos com os quais a criança se possa identificar, pelo que as respostas podem não refletir a perspetiva das próprias crianças perante a situação hipotética, mas concreta, da morte de alguém familiar. Além disso, alguns autores defendem que, embora quase inevitável, o medo da morte é sobretudo social, sendo adquirido essencialmente através de experiências indiretas (não pessoais) e de meios secundários (como os media), surgindo, por isso, mais tarde, por volta dos 5 - 6 anos de idade. ${ }^{19-22}$

O facto de as crianças em idade pré-escolar, independentemente da idade, identificarem como convencional a reação de tristeza perante a morte, vem também sustentar a ideia de que mesmo as crianças mais pequenas a sentem. Efetivamente, uma elaboração cognitiva limitada da morte não parece impedir a sua perceção, mesmo quando não há qualquer explicação do ambiente: por um lado, as crianças notam as emoções das pessoas à sua volta, absorvendo a sua preocupação e ansiedade; por outro lado, as próprias crianças sentem a perda que a morte implica. ${ }^{21}$

Paralelamente, embora em número reduzido, a existência de algumas respostas confusas, ou a ausência de resposta, sustenta a ideia de que, tal como outros domínios do desenvolvimento da criança, também o desenvolvimento emocional segue uma sequência previsível, mas não é inteiramente invariante, pelo que, em cada caso, deve ser feita uma avaliação individualizada. ${ }^{23}$ Assim, a resposta de cada criança é única, dependendo do seu temperamento, ambiente, experiências prévias e nível de desenvolvimento psicológico. Portanto, o ajustamento à morte deve ser avaliado de acordo com estas variáveis e não segundo uma imposição da vivência do adulto. ${ }^{21}$
Embora a idade, por si, não pareça influenciar a compreensão emocional sobre a morte, constatámos que em situações de maior compreensão emocional, a dimensão cognitiva está, também, significativamente mais desenvolvida, apontando para uma possível ligação entre estas duas dimensões. Assim, este estudo traz um contributo importante e inovador à investigação da dimensão emocional da morte, demonstrando a sua relação com a aproximação cognitiva, sobre a qual se têm maioritariamente, e de um modo isolado, debruçado os estudos nesta área.

Quanto ao facto de a maioria das crianças considerar que, perante a situação de morte de um familiar, a criança deve ser informada, destacamos expressões como “(...) senão ela depois não sabia" e "(...) porque ela pode pensar que a tia não está morta e está”, nas quais está patente a ideia do direito à verdade, a não ser enganado. No entantosabemos que na sociedade ocidental atual, os adultos tendem a excluir as crianças quando alguém próximo morre, tentando protegê-las do sofrimento..$^{24,25}$ De facto, nas respostas das poucas crianças que referem que os pais não devem contar o sucedido, parece estar subjacente essa ideia de proteção emocional (p. ex. "Não devem contar porque senão ela fica ainda mais triste"), alinhada com a atitude dos adultos. No entanto, os adultos esquecem-se que as crianças também sentem a perda e elaboram o seu próprio luto. ${ }^{25}$ Embora desejando proteger as crianças do sofrimento, a omissão destes sentimentos desagradáveis não os ajuda a expressar as suas emoções, restringindo, possivelmente, a resiliência que a sua experiência pode propiciar. ${ }^{25,26}$ Efetivamente, a dor e o sofrimento são recorrentes na vida, devendo os adultos ajudar as crianças a desenvolver as competências adequadas para reconhecer, expressar e lidar com essas emoções. ${ }^{26}$

A este comportamento de evicção do tema da morte com as crianças subjaz uma dimensão antropológica, associada a uma resistência geral da sociedade ocidental atual em falar da morte, ${ }^{24,27}$ ao contrário do que acontecia previamente ao século XIX, na sociedade ocidental, em que a morte era considerada um processo natural e aceite como tal. ${ }^{23,24}$ Alguns autores atribuem este fenómeno à mudança no paradigma de valores na sociedade ocidental, com a instalação da secularização e a primazia do desenvolvimento científico e tecnológico, ${ }^{23,24}$ tendo passado a morte a ser vista como um fim sem sentido, um falhanço da medicina moderna. ${ }^{27}$ Pelas emoções não desejadas que suscita, incluindo angústia, tristeza, medo e perda de esperança, propósito e identidade, a morte foi-se progressivamente tornando um tabu, o que prejudica a elaboração natural dos conceitos da morte e do luto. ${ }^{21,25,27}$ Neste contexto, não surpreende que os adultos procurem proteger as crianças da morte. ${ }^{24}$ Adicionalmente, a convicção comum de que as crianças não têm ainda as competências cognitivas e emocionais adequadas, reforça a evicção de conversas sobre a morte com elas. ${ }^{21}$ Contudo, este estudo e outros recentes ${ }^{9,28}$ mostram que mesmo crianças mais pequenas têm, efetivamente, conceções importantes sobre a morte, que não podem ser negligenciadas. Adicionalmente, 
a evidência mostra que apesar das tentativas de proteção dos adultos, as crianças são constantemente expostas à morte (quer na ficção, como na vida real), ${ }^{29}$ sabendo, quase sempre, mais do que aquilo que os cuidadores creem que elas sabem. ${ }^{23}$ Além disso, as crianças são muito curiosas em relação à morte, querendo saber o que é e por que motivo acontece. ${ }^{30}$ Recomenda-se que os adultos agarrem essas oportunidades para falar com elas, de modo adaptado ao seu nível de desenvolvimento, favorecendo a sua compreensão, tanto ao nível cognitivo como emocional. ${ }^{21}$

Algumas particularidades do desenvolvimento emocional normativo, não totalmente atendidas neste estudo, devem ser elencadas. Efetivamente, nas respostas dos participantes às questões do foro emocional, não realizámos a discriminação entre uma resposta espontânea ou a escolha de uma emoção de um conjunto de possibilidades, o que poderia, na verdade, refletir estádios de desenvolvimento diferentes (no primeiro caso, a criança reconhece a emoção, identificando-se, eventualmente, com a mesma, ao passo que, no segundo, é ajudada a fazê-lo). Adicionalmente, linguagem e pensamento não são necessariamente sobreponíveis. Assim, face à complexidade do desenvolvimento emocional, a que acresce o facto de as crianças estudadas se encontram numa situação de simulação, importa ressalvar que este estudo é apenas aproximativo à questão da morte.

No futuro, a investigação deve explorar o modo como esta compreensão emocional da morte ocorre no contexto sociocultural da criança, pesquisando as variáveis que influenciam essa aquisição. Efetivamente, o entendimento das crianças sobre a vida e a morte parece estar relacionado com as visões dos que as rodeiam, através de mecanismos sociais subtis que vão além do ensinamento direto. ${ }^{1}$ Adicionalmente, importa também aprofundar o modo como aspetos pessoais influenciam a compreensão de morte, nomeadamente a vivência de morte de alguém próximo e a experiência de doença grave ou hospitalização do próprio. De um modo geral, a compreensão da morte e do processo de morrer pelas crianças deve envolver uma investigação multidisciplinar, na medida em que este é um assunto com que diversas áreas, como a sociologia, antropologia, comunicação, filosofia, desenvolvimento infantil e cuidados de saúde se confrontam. ${ }^{3}$ Portanto, contrariamente ao que tem sido a regra, uma investigação nesta área deve seguir uma abordagem comunitária, ao mesmo tempo que olha a criança como um todo. Esta combinação permite ir além de variáveis fragmentadas, contextualizando os achados do desenvolvimento cognitivo numa perspetiva sociocultural mais ampla. ${ }^{4}$

\section{CONCLUSÃO}

Em suma, partindo de uma perspetiva de base emocional e explorando a sua interação com a dimensão cognitiva, este estudo sedimenta a conclusão de que as crianças não desenvolvem a sua compreensão da morte num vácuo afetivo, sendo as crianças em idade pré-escolar, mesmo as mais pequenas, capazes de uma leitura emocional adequada perante o cenário de morte de alguém próximo. Adicionalmente, destaca-se o facto de as crianças reconhecerem que devem ser informadas sobre a morte.

No que concerne à prática clínica, importa salientar que compreender o que as crianças sabem sobre a morte, como comunicam essas ideias e expressam as suas emoções é fundamental na abordagem comunicacional à criança em Cuidados Paliativos Pediátricos. Acresce que a utilidade desta evidência científica pode ser transversal a outras áreas, nomeadamente ao aconselhamento no luto infantil. Assim, os resultados deste estudo fornecem informação valiosa aos profissionais de saúde, famílias e outros adultos interessados, sobre a forma como a criança em idade pré-escolar se posiciona em relação à morte.

\section{PROTECÇÃO DE PESSOAS E ANIMAIS}

Os autores declaram que os procedimentos seguidos estavam de acordo com os regulamentos estabelecidos pelos responsáveis da Comissão de Investigação Clínica e Ética e de acordo com a Declaração de Helsínquia da Associação Médica Mundial.

\section{CONFIDENCIALIDADE DOS DADOS}

Os autores declaram ter seguido os protocolos do seu centro de trabalho acerca da publicação de dados.

\section{CONFLITOS DE INTERESSE}

Os autores declaram não ter conflitos de interesses relacionados com o presente trabalho.

\section{FONTES DE FINANCIAMENTO}

Este trabalho não recebeu qualquer tipo de suporte financeiro de nenhuma entidade no domínio público ou privado.

\section{REFERÊNCIAS}

1. Bates A, Kearney J. Understanding death with limited experience in life: dying children's and adolescents' understanding of their own terminal illness and death. Curr Opin Support Palliat Care. 2015;9:40-5.

2. Kenyon BL. Current research in children's conceptions of death: a critical review. OMEGA - J Death Dying. 2001;43:63-91.

3. Downing J, Knapp C, Muckaden MA, Fowler-Kerry S, Marston J, Committee IS. Priorities for global research into children's palliative care: results of an International Delphi study. BMC Palliat Care. 2015;14:36.

4. Callanan M. Diversity in children's understanding of death. Monogr Soc Res Child Dev. 2014;79:142-50.
5. Himelstein B, Hilden J, Boldt A, Weissman D. Pediatric palliative care. N Engl J Med. 2004;350:1752-62.

6. Slaughter V, Griffiths M. Death understanding and fear of death in young children. Clin Child Psychol Psychiatr. 2007;12:525-35.

7. Nguyen S, Gelman S. Four and 6-year olds' biological concept of death: the case of plants. Br J Devel Psychol. 2002;20:495-513.

8. Speece M, Brent S. The acquisition of a mature understanding of three components of the concept of death. Death Studies. 1992;16:211-29.

9. Rosengren K, Miller P, Gutiérrez I, Chow P, Schein S, Anderson K. Children's understanding of death: toward a contextualized and 
integrated account. Monogr Soc Res Child Dev. 2014;79:1-162.

10. Erikson R, Goldthorpe JH. The constant flux: a study of class mobility in industrial societies. Oxford: Oxford University Press; 1992.

11. Martins I. Censos 2011 - Mudanças demográficas. In: Urbano DM, editor. Porto: Câmara Municipal do Porto; 2014

12. Speece M, Brent S. The development of children's understanding of death. Handbook of childhood death and bereavement. New York: Springer Publishing Co; 1996.

13. Speece M, Brent S. Children's understanding of death: a review of three components of a death concept. Child Development. 1984;55:1671-86.

14. Bryman A. Qualitative data analysis. Social research methods. New York: Oxford University Press; 2012:565-89.

15. Taylor-Powell E, Renner M. Analyzing qualitative data. Madison: University of Wisconsin, 2003.

16. Gutiérrez I, Miller P, Rosengren K, Schein S. III. Affective dimensions of death: children's books, questions, and understandings. Monogr Soc Res Child Dev. 2014;79:43-61.

17. Cotton C, Range L. Children's death concepts: relationship to cognitive functioning, age, experience with death, fear of death, and hopelessness. J Clin Child Psychol. 1990;19:123-7.

18. Orbach I, Gross Y, Glaubman H, Berman D. Children's perception of death in humans and animals as a function of age, anxiety and cognitive ability. J Child Psychol Psychiatry. 1985;26:453-63.

19. Bryant C, Peck D. Encyclopedia of death and the human experience. Thousand Oaks: SAGE Publications; 2009.

20. González Sánchez I, de la Herrán Gascón A. Introducción metodológica a la muerte y los miedos en educación infantil. Tendencias Pedagógicas.
2010;15:26

21. Gorosabel-Odriozola M, León-Mejía A. La muerte en educación infantil: algunas líneas básicas de actuación para centros escolares. Psicol Educ. 2016;22:103-11.

22. Kübler-Ross E. On children and death: how children and their parents can and do cope with death. New York: Scribner; 1997.

23. Norero V. La maduración cerebral en el niño. El caso de la adquisición del concepto de muerte y su evolución. Rev Chil Pediatr. 2018;89:13742.

24. Ariès $P$. Western attitudes toward death: from the middle ages to the present. Baltimore: Johns Hopkins University Press; 1974.

25. Ramos-Pla A, Gairín J, Camats R. Principios prácticos y funcionales en situaciones de muerte y duelo para profesionales de la educación. REICE. 2018;16.

26. Wu G, Feder A, Cohen H, Kim J, Calderon S, Charney DS, et al. Understanding resilience. Front Behav Neurosci. 2013;7:10.

27. Aynsley-Green SA. Think adult-think child! Why should staff caring for dying adults ask what the death means for children in the family? $\mathrm{Br}$ Med Bull. 2017;123:5-17.

28. Talwar V, Harris P, Schleifer M. Children's understanding of death: from biological to religious conceptions. Cambridge: Cambridge University Press; 2011.

29. Bluebond-Langner M, Schwallie M. Children's experience of death In: Shweder R, ed. The child: an encyclopedic companion. Chicago: University of Chicago Press; 2009:240-2.

30. Christ GH. Impact of development on children's mourning. Cancer Pract. 2000;8:72-81. 